\title{
Association between health behaviours and depression: findings from a national cross- sectional study in South Korea
}

\author{
Bich Na Jang ${ }^{1,2}$, Hyeon Ji Lee ${ }^{1,2}$, Jae Hong Joo ${ }^{1,2}$, Eun-Cheol Park ${ }^{2,3}$ and Sung-In Jang ${ }^{2,3^{*}}$ (D)
}

\begin{abstract}
Background: Depression is a leading cause of disability, and it has been reported that more than 264 million people worldwide have depression. The causes of depression may be numerous, and physical health has also been linked to depression. Therefore, the aim of this study was to determine the effect of health behaviours on depression.

Methods: This study used the data of 224,868 participants from the Community Health Survey, conducted in 2017. We defined health behaviours by combining three variables: no smoking, not belonging to high-risk drinking group, and walking frequently. Depression was measured using the Patient Health Questionnaire-9. Logistic regression was used to examine the association between health behaviours and depression.

Results: Both men and women who did not practise health behaviours were more likely to experience depressive symptoms than those who did (men, odds ratio (OR): 1.48, 95\% confidence interval (Cl): 1.31-1.68; women, OR: 1.42, 95\% Cl: 1.32-1.53). Not walking frequently had the strongest association with depression in men and the risk of depression was the highest in women who smoked. Participants who did not practise any health behaviours were the most likely to have depressive symptoms (men, OR: 1.69, 95\% Cl: 1.38-2.07; women, OR: 3.08, 95\% Cl: 2.27-4.19).

Conclusion: Our study found that lack of health behaviours is significantly associated with depression. Furthermore, the most influential factor of health behaviours in depression was different for men and women. It is necessary to manage depression through interventional methods customised to gender characteristics. Additionally, nationallevel policies are needed to encourage steps to improve personal lifestyles, including practising health behaviours.
\end{abstract}

Keywords: Health behaviour, Depression, Walking, Smoking, Alcohol drinking

\section{Background}

Suicide is a serious public health problem worldwide. South Korea is the nation with the major suicide rate (24.6 deaths per 100,000 people) among the Organization for Economic Co-operation and Development (OECD)

\footnotetext{
* Correspondence: JANGSI@yuhs.ac

${ }^{2}$ Institute of Health Services Research, Yonsei University, Seoul, Republic of Korea

${ }^{3}$ Department of Preventive Medicine and Institute of Health Services

Research, Yonsei University College of Medicine, 50 Yonsei-ro, Seodaemun-gu, Seoul 03722, South Korea

Full list of author information is available at the end of the article
}

nations [1]. Depression is one of the most common mental health disorders. It is a leading cause of disability and suicide and it has been reported that more than 264 million people worldwide have depression [2]. Depression also causes other unfavorable outcomes in terms of role functioning, quality of life, and many long-lasting physical health problems [3].

Poor physical health is closely related with depression. It is a well-known fact that people with chronic diseases have a greater tendency to be depressed than healthy people. Cardiovascular diseases such as acute myocardial 
infarction and stroke and cancer are associated with depression and people who were not depressed prior to having such diseases would develop depression [4-8].

Health behaviour is any activity undertaken by an individual for the purpose of maintaining health and preventing illness [9]. For example, prior research has shown that a variety of health behaviours, including physical activity, are related to depression [10]. Another study proved that an inverse relationship existed between the amount of leisure-time physical activity and symptoms of depression [11]. In addition, people who had depression were more likely to enjoy smoking and drinking [12]. A longitudinal study found that those who had never smoked before the onset of depressive symptoms tended to be more dependent on tobacco than those who smoked before [13]. Such a tendency would eventually lead to poor physical health.

It is important to implement early interventions for depression to get better outcomes [14]. A few countries have made impressive progress in establishing and publishing mental health data for qualifying for care [15]. In South Korea, a substantial number of people have depression [16]; therefore, the government is progressing care for mental disorders from primary to tertiary [17]. However, a national strategic approach in mental health care is still lacking among OECD nations. While localised efforts have been undertaken to improve the collection of indicators of quality of mental health care, such steps are not carried out at the national level [15].

Interventions for reducing depressive symptoms are various and extensive [18]. To find out the most effective way, we should understand the association between health behaviours and depression. As mentioned above, several studies have found an association between health behaviours and depression. However, there is limited research on the association between a combination of health behaviours and depression.

We formed a hypothesis that the fewer the health behaviours practised, the higher the risk of depression. Thus, this study's main objective is to determine the most influential health behaviours among people with depression and those without. Moreover, previous studies have indicated gender differences in depression [19, 20]. Therefore, our second objective is to investigate the association between health behaviours and depression stratified by gender.

\section{Methods}

\section{Study population}

This study used data from the Korea Community Health Survey (KCHS) conducted in 2017. This survey has been conducted annually by the Korean Centers for Disease Control and Prevention for adults aged 19 or older since 2008 to establish and evaluate regional health plans and standardise the survey performance system to produce comparable regional health statistics [21]. The CHS data used in this study included 201 questions across 18 fields such as health behaviours, physical activities, medical service use, and social environments. The data were not reviewed by an institutional review board on the basis of the Bioethics Act and Article 2 of its enforcement regulations.

The total population was 228,381 participants; we excluded participants who had received expert consultation associated with sadness or hopelessness for more than two weeks in the previous year $(n=2594)$ to detect new onset of depression. In addition, we omitted those who answered 'don't know' or rejected responses to the questions or had missing data to the questions included in this study $(n=4165)$. Finally, a total of 221,622 participants (99,852 men, 121,770 women) were selected (Fig. 1).

\section{Variables}

To define health behaviours, we combined three variables suggested by the CHS survey: No smoking, not belonging to high-risk drinking group, and walking frequently. No smoking meant not smoking at the time of investigation and those who had ' 0 ' pack-year. Packyear is a method of measuring the amount of cigarettes a person has smoked and calculated by multiplying the number of packs of cigarette smoked per day by the number of years of smoking [22]. We combined these two indicators to assess the exact exposure status of smoking. Not belonging to high-risk drinking group meant being a non-drinker or drinking under five shots (for women) or under seven shots (for men) in a single sitting and having drinks less than one time per week. Walking frequently was defined as walking over $30 \mathrm{~min}$ daily more than five days in the last week. Participants who met all three of the above conditions belonged to the practising-health-behaviour group, while those who failed to meet any of the above conditions belonged to the not-practising-health-behaviour group.

The Patient Health Questionnaire-9 (PHQ-9) is a selfadministered questionnaire comprising nine questions to evaluate depressive symptoms [23]. For detecting depression, we used the Korean version of PHQ-9, whose validity and reliability has been proven [24]. The score ranges from 0 to 27 , and more than 10 points is classified as depression [23]. We divided the participants into two groups according to the score: Have depressive symptoms and no depressive symptoms.

Other covariates were included in the analysis as potential confounding variables: sex, age, marital status, region, occupation category, educational level, household income, body mass index, comorbidity, perceived health status, and perceived stress level. Occupation was 


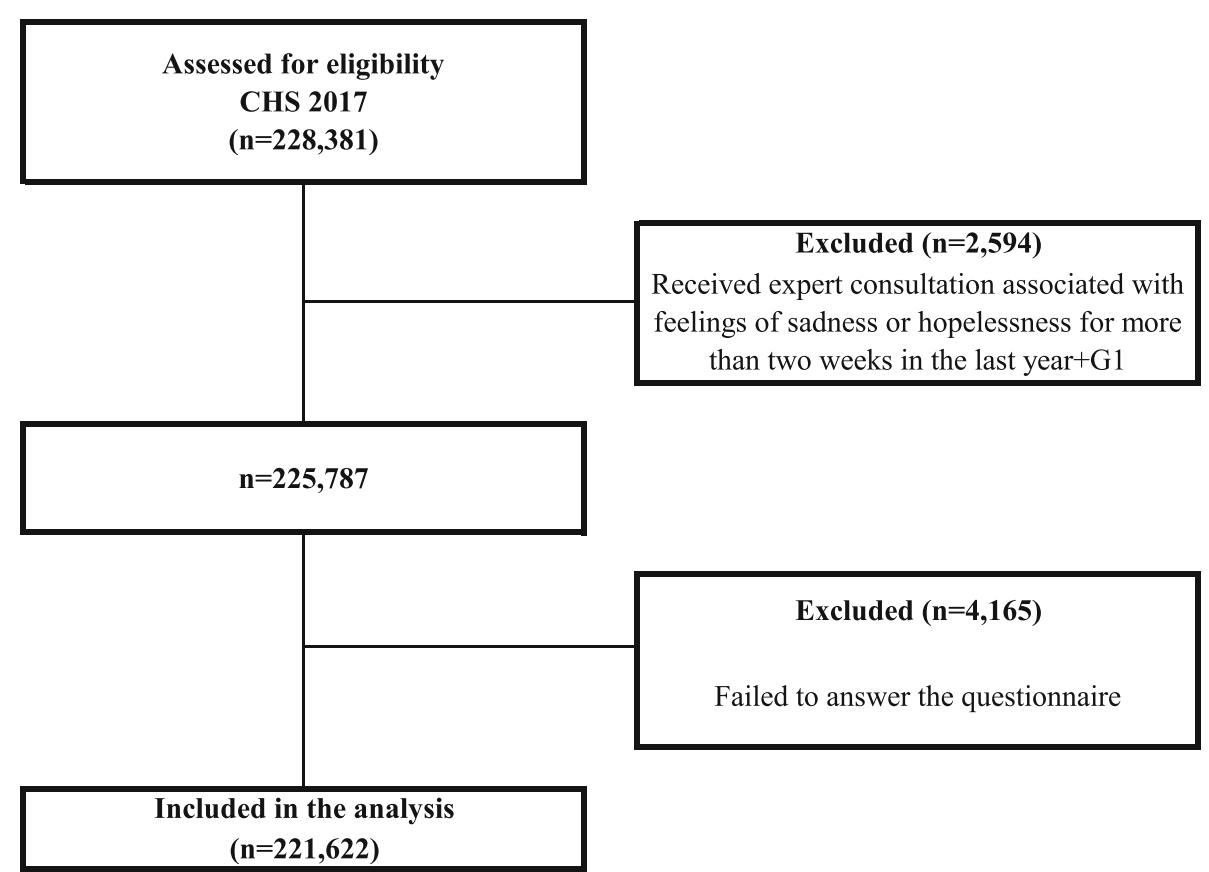

Fig. 1 Flow diagram of subject inclusion and exclusion CHS: Community Health Survey

categorised according to the Korean version of the Standard Classification of Occupations, based on the International Standard Classification of Occupations by the International Labour Organization. We recategorised occupation into four categories: White (office work), Pink (sales and service), Blue (agriculture, forestry, fishery, and armed forces occupation), and inoccupation. Comorbidity included hypertension, diabetes mellitus, hyperlipidaemia, and arthritis, and we calculated the number of comorbid diseases that one person had simultaneously.

\section{Statistical analysis}

The covariates were compared using the chi-squared test to confirm association between health behaviours and depression. After adjusting for demographic, socioeconomic. and health-related variables, we used multiple logistic regression analysis to evaluate the association between health behaviours and depression. The results were reported using odds ratios (ORs) and confidence intervals (CIs). Subgroup analysis was also performed stratified by gender and other covariates. In addition, each factor of a health behaviour was analysed through multiple logistic regression analysis to determine which factor was the most relevant to depression. Furthermore, to determine a better-fitting model including all the above-mentioned variables, we examined the Akaike Information Criteria to compare models (Table 1 in the supplementary materials). Differences were considered statistically significant at $p$-values of $<0.05$. All statistical analyses were performed using SAS software (version 9.4, SAS Institute, Cary, NC, USA).

\section{Results}

For the purpose of this study, we analysed each variable according to gender. Table 1 shows general characteristics of the study population. Among the 221,622 study participants, 2152 men (2.2\%) and 4443 women (3.6\%) met the criteria for depression. The number of participants in the not-practising-health-behaviours group was 75,812 men $(75.9 \%)$ and 78,939 women $(64.8 \%)$. In the not-practising-health-behaviours group, 1809 (2.4\%) of men and 3361 (4.3\%) of women had depressive symptoms. On the other hand, $343(1.4 \%)$ of men and 1082 $(2.5 \%)$ of women who met the criteria for depression were in the practising-health-behaviours group.

The OR of factors associated with depression and determined using multiple logistic regression analysis are shown in Table 2. Both men and women who did not practise health behaviours were more likely to have depressive symptoms than people who practised health behaviours (men, OR: 1.48, 95\% CI: 1.31-1.68; women, OR: 1.42 , 95\% CI: 1.32-1.53). In addition, participants who had more chronic diseases, whose perceived health status was bad, or substantial stress were likely to be depressed.

Table 3 presents the association between individual criteria of health behaviours and depression stratified by gender. Among men, not walking frequently was the most influential factor associated with depression than 
Table 1 General characteristics of the study population

\begin{tabular}{|c|c|c|c|c|c|c|c|c|c|c|c|c|c|c|}
\hline \multirow[t]{4}{*}{ Variables } & \multicolumn{14}{|c|}{ Depression } \\
\hline & \multicolumn{7}{|l|}{ Male } & \multicolumn{7}{|l|}{ Female } \\
\hline & \multicolumn{2}{|l|}{ TOTAL } & \multicolumn{2}{|l|}{ Yes } & \multicolumn{2}{|l|}{ No } & \multirow[t]{2}{*}{ P-value } & \multicolumn{2}{|l|}{ TOTAL } & \multicolumn{2}{|l|}{ Yes } & \multicolumn{2}{|l|}{ No } & \multirow[t]{2}{*}{$P$-value } \\
\hline & $\mathrm{N}$ & $\%$ & $\mathrm{~N}$ & $\%$ & $\mathrm{~N}$ & $\%$ & & $\mathrm{~N}$ & $\%$ & $\mathrm{~N}$ & $\%$ & $\mathrm{~N}$ & $\%$ & \\
\hline $\operatorname{Total}(N=221,622)$ & 99,852 & 100.0 & 2152 & 2.2 & 97,700 & 97.8 & & 121,770 & 100.0 & 4443 & 3.6 & 117,327 & 96.4 & \\
\hline Health behaviours ${ }^{a}$ & & & & & & & $<0.0001$ & & & & & & & $<0.0001$ \\
\hline Yes & 24,040 & 24.1 & 343 & 1.4 & 23,697 & 98.6 & & 42,831 & 35.2 & 1082 & 2.5 & 41,749 & 97.5 & \\
\hline No & 75,812 & 75.9 & 1809 & 2.4 & 74,003 & 97.6 & & 78,939 & 64.8 & 3361 & 4.3 & 75,578 & 95.7 & \\
\hline Age (years) & & & & & & & $<0.0001$ & & & & & & & $<0.0001$ \\
\hline $19-29$ & 11,157 & 11.2 & 249 & 2.2 & 10,908 & 97.8 & & 12,476 & 10.2 & 571 & 4.6 & 11,905 & 95.4 & \\
\hline $30-39$ & 13,706 & 13.7 & 254 & 1.9 & 13,452 & 98.1 & & 15,405 & 12.7 & 406 & 2.6 & 14,999 & 97.4 & \\
\hline $40-49$ & 18,051 & 18.1 & 232 & 1.3 & 17,819 & 98.7 & & 20,344 & 16.7 & 364 & 1.8 & 19,980 & 98.2 & \\
\hline $50-59$ & 20,094 & 20.1 & 308 & 1.5 & 19,786 & 98.5 & & 23,692 & 19.5 & 531 & 2.2 & 23,161 & 97.8 & \\
\hline$\geq 60$ & 36,844 & 36.9 & 1109 & 3.0 & 35,735 & 97.0 & & 49,853 & 40.9 & 2571 & 5.2 & 47,282 & 94.8 & \\
\hline Marital Status & & & & & & & $<0.0001$ & & & & & & & $<0.0001$ \\
\hline Living with spouse & 72,806 & 72.9 & 1252 & 1.7 & 71,554 & 98.3 & & 77,342 & 63.5 & 1968 & 2.5 & 75,374 & 97.5 & \\
\hline Living without spouse & 27,046 & 27.1 & 900 & 3.3 & 26,146 & 96.7 & & 44,428 & 36.5 & 2475 & 5.6 & 41,953 & 94.4 & \\
\hline Region & & & & & & & 0.4589 & & & & & & & 0.0300 \\
\hline Metropolitan area & 29,861 & 29.9 & 628 & 2.1 & 29,233 & 97.9 & & 36,647 & 30.1 & 1272 & 3.5 & 35,375 & 96.5 & \\
\hline Rural & 69,991 & 70.1 & 1524 & 2.2 & 68,467 & 97.8 & & 85,123 & 69.9 & 3171 & 3.7 & 81,952 & 96.3 & \\
\hline Occupational categories ${ }^{\mathrm{b}}$ & & & & & & & $<0.0001$ & & & & & & & $<0.0001$ \\
\hline White & 22,866 & 22.9 & 220 & 1.0 & 22,646 & 99.0 & & 21,160 & 17.4 & 457 & 2.2 & 20,703 & 97.8 & \\
\hline Pink & 10,382 & 10.4 & 163 & 1.6 & 10,219 & 98.4 & & 18,084 & 14.9 & 440 & 2.4 & 17,644 & 97.6 & \\
\hline Blue & 42,702 & 42.8 & 607 & 1.4 & 42,095 & 98.6 & & 25,984 & 21.3 & 683 & 2.6 & 25,301 & 97.4 & \\
\hline Inoccupation & 23,902 & 23.9 & 1162 & 4.9 & 22,740 & 95.1 & & 56,542 & 46.4 & 2863 & 5.1 & 53,679 & 94.9 & \\
\hline Educational level & & & & & & & $<0.0001$ & & & & & & & $<0.0001$ \\
\hline Middle school or less & 26,477 & 26.5 & 985 & 3.7 & 25,492 & 96.3 & & 51,514 & 42.3 & 2690 & 5.2 & 48,824 & 94.8 & \\
\hline High school & 31,315 & 31.4 & 577 & 1.8 & 30,738 & 98.2 & & 31,466 & 25.8 & 810 & 2.6 & 30,656 & 97.4 & \\
\hline College or over & 42,060 & 42.1 & 590 & 1.4 & 41,470 & 98.6 & & 38,790 & 31.9 & 943 & 2.4 & 37,847 & 97.6 & \\
\hline Household income & & & & & & & $<0.0001$ & & & & & & & $<0.0001$ \\
\hline Low & 16,115 & 16.1 & 940 & 5.8 & 15,175 & 94.2 & & 28,027 & 23.0 & 1978 & 7.1 & 26,049 & 92.9 & \\
\hline Mid-low & 34,409 & 34.5 & 644 & 1.9 & 33,765 & 98.1 & & 39,101 & 32.1 & 1315 & 3.4 & 37,786 & 96.6 & \\
\hline Mid-high & 29,230 & 29.3 & 346 & 1.2 & 28,884 & 98.8 & & 32,080 & 26.3 & 718 & 2.2 & 31,362 & 97.8 & \\
\hline High & 20,098 & 20.1 & 222 & 1.1 & 19,876 & 98.9 & & 22,562 & 18.5 & 432 & 1.9 & 22,130 & 98.1 & \\
\hline Obesity Status (BMI) & & & & & & & $<0.0001$ & & & & & & & $<0.0001$ \\
\hline Underweight and Normal range & 38,382 & 38.4 & 1143 & 3.0 & 37,239 & 97.0 & & 69,975 & 57.5 & 2689 & 3.8 & 67,286 & 96.2 & \\
\hline Overweight & 28,040 & 28.1 & 430 & 1.5 & 27,610 & 98.5 & & 25,518 & 21.0 & 740 & 2.9 & 24,778 & 97.1 & \\
\hline Obese & 33,430 & 33.5 & 579 & 1.7 & 32,851 & 98.3 & & 26,277 & 21.6 & 1014 & 3.9 & 25,263 & 96.1 & \\
\hline The number of chronic diseases ${ }^{d}$ & & & & & & & $<0.0001$ & & & & & & & $<0.0001$ \\
\hline 0 & 59,400 & 59.5 & 968 & 1.6 & 58,432 & 98.4 & & 66,411 & 54.5 & 1685 & 2.5 & 64,726 & 97.5 & \\
\hline 1 & 23,901 & 23.9 & 581 & 2.4 & 23,320 & 97.6 & & 27,133 & 22.3 & 1087 & 4.0 & 26,046 & 96.0 & \\
\hline$\geq 2$ & 16,551 & 16.6 & 603 & 3.6 & 15,948 & 96.4 & & 28,226 & 23.2 & 1671 & 5.9 & 26,555 & 94.1 & \\
\hline Perceived health status & & & & & & & $<0.0001$ & & & & & & & $<0.0001$ \\
\hline Good & 42,332 & 42.4 & 209 & 0.5 & 42,123 & 99.5 & & 39,527 & 32.5 & 419 & 1.1 & 39,108 & 98.9 & \\
\hline Bad & 57,520 & 57.6 & 1943 & 3.4 & 55,577 & 96.6 & & 82,243 & 67.5 & 4024 & 4.9 & 78,219 & 95.1 & \\
\hline
\end{tabular}


Table 1 General characteristics of the study population (Continued)

\begin{tabular}{|c|c|c|c|c|c|c|c|c|c|c|c|c|c|c|}
\hline \multirow[t]{4}{*}{ Variables } & \multicolumn{14}{|c|}{ Depression } \\
\hline & \multicolumn{7}{|l|}{ Male } & \multicolumn{7}{|l|}{ Female } \\
\hline & \multicolumn{2}{|l|}{ TOTAL } & \multicolumn{2}{|l|}{ Yes } & \multicolumn{2}{|l|}{ No } & \multirow[t]{2}{*}{ P-value } & \multicolumn{2}{|l|}{ TOTAL } & \multicolumn{2}{|l|}{ Yes } & \multicolumn{2}{|l|}{ No } & \multirow[t]{2}{*}{ P-value } \\
\hline & $\mathrm{N}$ & $\%$ & $\mathrm{~N}$ & $\%$ & $\mathrm{~N}$ & $\%$ & & $\mathrm{~N}$ & $\%$ & $\mathrm{~N}$ & $\%$ & $\mathrm{~N}$ & $\%$ & \\
\hline Perceived stress & & & & & & & $<0.0001$ & & & & & & & $<0.0001$ \\
\hline Substantial & 22,530 & 22.6 & 1531 & 6.8 & 20,999 & 93.2 & & 28,889 & 23.7 & 3121 & 10.8 & 25,768 & 89.2 & \\
\hline Less & 77,322 & 77.4 & 621 & 0.8 & 76,701 & 99.2 & & 92,881 & 76.3 & 1322 & 1.4 & 91,559 & 98.6 & \\
\hline
\end{tabular}

${ }^{a}$ Those classified as practising-health-behaviours group met all three conditions: not smoking (or 0 pack-year), not belonging to high-risk drinking group and walking for 30 min over 5 days per week

${ }^{\mathrm{b}}$ Three groups (white, pink, blue) based on the International Standard Classification Occupations codes. Inoccupation group includes housewives CBMI Body mass index/obesity status defined by BMI based on the 2018 Clinical Practice Guidelines for Overweight and Obesity in Korea

${ }^{\mathrm{d} C h r o n i c ~ d i s e a s e ~ w a s ~ d e f i n e d ~ a s ~ d i a g n o s e d ~ d i s e a s e s: ~ h y p e r t e n s i o n, ~ d i a b e t e s ~ m e l l i t u s, ~ h y p e r l i p i d a e m i a ~ a n d ~ a r t h r i t i s . ~ T h e ~ n u m b e r ~ o f ~ c h r o n i c ~ d i s e a s e s e ~ i s ~ t h e ~ s u m ~ o f ~}$ the number of diagnosed above diseases

other factors (not walking frequently, OR: 1.32, 95\% CI: 1.20-1.46; smoking, OR: $1.17,95 \%$ CI: 1.06-1.29; highrisk drinking, OR: $1.09,95 \%$ CI: 0.97-1.23), while smoking was the most powerful factor in women (smoking, OR: 1.99, 95\% CI: 1.75-2.26; high-risk drinking, OR: 1.43, 95\% CI: 1.25-1.65; not walking frequently, OR: 1.25, 95\% CI: 1.17-1.34). However, men who did not practise all of the health behaviours suggested in this study had the most powerful association with depression. In contrast, in women, only one factor, smoking, was more powerful than not practising all of the health behaviours.

The combination of each factor of health behaviours and its relation to depression is shown in Fig. 2. As can be seen from the figure, fewer the health behaviours practised, greater was the relation to depression. Moreover, participants who never practised health behaviours were the most likely to have depressive symptoms (men, OR: 1.69 , 95\% CI: 1.38-2.07; women, OR: 3.08, 95\% CI: 2.27-4.19) (Table 2 in Supplement). The most influential factor among men and women in Fig. 1 had a thread of connection with Table 3.

The subgroup analysis stratified by independent variables is represented in Table 3 of Supplement. We examined variables related to health behaviours and confirmed the association of depression in most notpractising-health-behaviours groups compared to practising-health-behaviours groups.

\section{Discussion}

The present study was designed to determine the association between health behaviours and depression in a large population-based sample. The results showed that not practising health behaviours was significantly associated with depression among Korean adults. The ORs of association between health behaviours and depression were higher in men than in women.

To confirm the most influential factor of health behaviours, we analysed the relationship between each factor and depression. Men and women had different results.
Not walking frequently was the most influential factor in men, and smoking was the most associated with depression in women. In other words, men who do not practise frequent physical activities are more associated with depression than those who do, and women who smoke are more likely to have depressive symptoms than those who are not smokers. However, men who did not practise all of the health behaviours suggested in this study, had a more powerful association with depression than only the not-walking-frequently group.

We further analysed the relationship between health behaviours and depression. There were different results for men and women, which could indicate different influences. However, in general, it has been shown that higher the number of not-practising-health-behaviours factors, the greater the association with depression. It means that practising good health behaviours is related to a decrease in depression.

Living without a spouse, having no jobs at that time, low educational status, low household income, comorbidity, perceived health status, and substantial perceived stress were associated with depression in this study. Further analysis showed that the participants, especially men, with worse health factors had a greater association with depression when they did not practise health behaviours.

Moreover, participants who had more chronic diseases and did not practise health behaviours were more associated with depression. According to several studies that explained the relationship between hypertension and depression, hypertension was significantly associated with depression because of abnormal circadian blood pressure [25], increasing sympathetic nervous system activity [26, 27], genetic factors [28], etc. Likewise, other chronic diseases included in this study were associated with depression [29-31].

Consistent with past studies, health behaviours selected in this study were confirmed to have a relationship with depression. First, smoking increases sympathetic nervous system activity [32] and could have 
Table 2 Results of factors associated with depression

\begin{tabular}{|c|c|c|c|c|c|c|c|c|}
\hline \multirow[t]{3}{*}{ Variables } & \multicolumn{8}{|c|}{ Depression } \\
\hline & \multicolumn{4}{|c|}{ Male } & \multicolumn{4}{|c|}{ Female } \\
\hline & OR & \multicolumn{3}{|c|}{$95 \% \mathrm{Cl}$} & OR & \multicolumn{3}{|c|}{$95 \% \mathrm{Cl}$} \\
\hline \multicolumn{9}{|l|}{ Total } \\
\hline \multicolumn{9}{|l|}{ Health behaviours ${ }^{a}$} \\
\hline Yes & 1.00 & & & & 1.00 & & & \\
\hline No & 1.48 & $(1.31$ & - & 1.68) & 1.42 & $(1.32$ & - & 1.53) \\
\hline \multicolumn{9}{|l|}{ Age (years) } \\
\hline $19-29$ & 1.00 & & & & 1.00 & & & \\
\hline $30-39$ & 1.03 & $(0.85$ & - & $1.26)$ & 0.67 & $(0.58$ & - & $0.77)$ \\
\hline $40-49$ & 0.62 & $(0.50$ & - & $0.76)$ & 0.47 & $(0.41$ & - & $0.55)$ \\
\hline $50-59$ & 0.57 & $(0.46$ & - & $0.71)$ & 0.45 & $(0.39$ & - & $0.53)$ \\
\hline$\geq 60$ & 0.61 & $(0.49$ & - & $0.76)$ & 0.45 & $(0.38$ & - & $0.54)$ \\
\hline \multicolumn{9}{|l|}{ Marital Status } \\
\hline Living with spouse & 1.00 & & & & 1.00 & & & \\
\hline Living without spouse & 1.59 & $(1.43$ & - & $1.77)$ & 1.63 & $(1.52$ & - & 1.75) \\
\hline \multicolumn{9}{|l|}{ Region } \\
\hline Metropolitan area & 1.00 & & & & 1.00 & & & \\
\hline Rural & 0.92 & $(0.83$ & - & $1.02)$ & 0.92 & $(0.85$ & - & $0.98)$ \\
\hline \multicolumn{9}{|l|}{ Occupational categories $^{\mathbf{b}}$} \\
\hline White & 1.00 & & & & 1.00 & & & \\
\hline Pink & 1.35 & $(1.09$ & - & 1.67) & 0.99 & $(0.86$ & - & 1.14) \\
\hline Blue & 1.21 & $(1.02$ & - & $1.45)$ & 0.88 & $(0.76$ & - & $1.02)$ \\
\hline Inoccupation & 3.07 & $(2.56$ & - & 3.69) & 1.69 & $(1.50$ & - & 1.91) \\
\hline \multicolumn{9}{|l|}{ Educational level } \\
\hline Middle school or less & 1.65 & $(1.41$ & - & 1.93) & 1.77 & $(1.53$ & - & 2.04) \\
\hline High school & 1.16 & $(1.01$ & - & 1.33) & 1.32 & $(1.18$ & - & 1.48) \\
\hline College or over & 1.00 & & & & 1.00 & & & \\
\hline \multicolumn{9}{|l|}{ Household income } \\
\hline Low & 2.21 & $(1.84$ & - & $2.66)$ & 1.89 & $(1.66$ & - & $2.16)$ \\
\hline Mid-low & 1.22 & $(1.03$ & - & 1.44) & 1.32 & $(1.17$ & - & 1.49) \\
\hline Mid-high & 0.99 & $(0.83$ & - & 1.18) & 1.09 & $(0.96$ & - & 1.24) \\
\hline High & 1.00 & & & & 1.00 & & & \\
\hline \multicolumn{9}{|l|}{ Obesity Status (BMI) ${ }^{d}$} \\
\hline Underweight and Normal range & 1.00 & & & & 1.00 & & & \\
\hline Overweight & 0.67 & $(0.59$ & - & $0.75)$ & 0.80 & $(0.73$ & - & $0.87)$ \\
\hline Obese & 0.69 & $(0.62$ & - & $0.78)$ & 0.87 & $(0.80$ & - & $0.94)$ \\
\hline \multicolumn{9}{|l|}{ The number of chronic diseases ${ }^{e}$} \\
\hline 0 & 1.00 & & & & 1.00 & & & \\
\hline 1 & 1.25 & $(1.11$ & - & 1.40) & 1.26 & $(1.14$ & - & 1.39) \\
\hline$\geq 2$ & 1.56 & $(1.38$ & - & 1.77) & 1.47 & $(1.33$ & - & 1.62) \\
\hline \multicolumn{9}{|l|}{ Perceived health status } \\
\hline Good & 1.00 & & & & 1.00 & & & \\
\hline Bad & 4.16 & $(3.58$ & - & 4.85) & 2.75 & $(2.47$ & - & 3.07) \\
\hline
\end{tabular}

Perceived stress 
Table 2 Results of factors associated with depression (Continued)

\begin{tabular}{|c|c|c|c|c|c|c|c|c|}
\hline \multirow[t]{3}{*}{ Variables } & \multicolumn{8}{|c|}{ Depression } \\
\hline & \multicolumn{4}{|c|}{ Male } & \multicolumn{4}{|c|}{ Female } \\
\hline & $\overline{O R}$ & \multicolumn{3}{|c|}{$95 \% \mathrm{Cl}$} & $\overline{\mathrm{OR}}$ & \multicolumn{3}{|c|}{$95 \% \mathrm{Cl}$} \\
\hline Substantial & 9.29 & $(8.41$ & - & 10.26) & 8.39 & (7.83 & - & 8.98) \\
\hline Less & 1.00 & & & & 1.00 & & & \\
\hline
\end{tabular}

${ }^{a}$ Those classified as practising-health-behaviours group met all three conditions: not smoking (or 0 pack-year), not belonging to high-risk drinking group and walking for 30 min over 5 days per week

${ }^{\mathrm{b}}$ Three groups (white, pink, blue) based on the International Standard Classification Occupations codes. Inoccupation group includes housewives

${ }^{\mathrm{c}} B M I$ Body mass index/obesity status defined by BMI based on the 2018 Clinical Practice Guidelines for

Overweight and Obesity in Korea

${ }^{\mathrm{d}}$ Chronic disease was defined diagnosed diseases: hypertension, diabetes mellitus, hyperlipidaemia and arthritis. The number of chronic diseasese is the sum of the number of diagnosed above diseases

an effect on depression. Second, physical inactivity is a leading cause of chronic disease [33], and participants in this study who had chronic diseases and did not practice health behaviours were vulnerable to depression [3437]. Additionally, a meta-analysis study found that exercise is an effective mediation for depression because it is related to expansion of brain capacity [38]. Lastly, a study considering people's drinking status, intensity, and frequency found that alcohol consumption is related to depression [39].

Some studies showed that interventions for reducing depression varied by subjects and objectives. Improving lifestyle, in particular, has been proven by previous studies to be effective in treating depression. Physical activity [40] intervention including walking [41] is effective in

Table 3 The results of subgroup anaylsis strafied by interesting variables*

\begin{tabular}{|c|c|c|c|c|c|c|c|c|}
\hline \multirow[t]{3}{*}{ Variables } & \multicolumn{8}{|c|}{ Depression } \\
\hline & \multicolumn{5}{|c|}{ Male } & \multicolumn{3}{|c|}{ Female } \\
\hline & $\overline{\mathrm{OR}}$ & $95 \% \mathrm{Cl}$ & & & OR & $95 \% \mathrm{Cl}$ & & \\
\hline \multicolumn{9}{|c|}{ High-risk drinking $^{a}$} \\
\hline Yes & 1.09 & $(0.97$ & - & $1.23)$ & 1.43 & $(1.25$ & - & 1.65) \\
\hline No & 1.00 & & & & 1.00 & & & \\
\hline \multicolumn{9}{|c|}{ Smoking status ${ }^{\mathrm{b}}$} \\
\hline Yes & 1.17 & $(1.06$ & - & 1.29) & 1.99 & $(1.75$ & - & 2.26) \\
\hline No & 1.00 & & & & 1.00 & & & \\
\hline \multicolumn{9}{|c|}{ Frequent walking ${ }^{c}$} \\
\hline Yes & 1.00 & & & & 1.00 & & & \\
\hline No & 1.32 & (1.20 & - & 1.46) & 1.25 & (1.17 & - & 1.34) \\
\hline
\end{tabular}

*Adjusted by variables including age, marital status, region, household income, job, educational status, pack year, BMI, physical activity, the number of chronic diseases, and perceived stress

${ }^{a}$ Defined as those who drink more than 1 day per week and have more than 5 shots (for women) or 7 shots (for men) Additionally adjusted by variables including smoking status and frequent walking

b Defined as those who do not smoke currently and pack year is ' 0 ', and additionally adjusted by variables including high-risk drinking and frequent walking

'Defined as those who walk for 30 min over per day and over 5 days per week. Additionally adjusted by variables including high risk drinking and smoking status reducing depression. In addition, management of recreational substances such as alcohol, cigarettes, and caffeine is effective in the treatment of depression [42].

The present study has several strengths. We used a large and nationally representative database [21] to determine lifestyle factors associated with depression. In addition, we used the PHQ-9, which is a reliable and valid tool for screening depressive patients than a selfreported questionnaire [43]. To our knowledge, this is the first study to determine the relationship between a health behaviours and depression, using the CHS data. In addition, we found that the most influential health behaviour factors in depression were different for men and women.

However, this study has some limitations. First, because this was a cross-sectional study, we could not prove whether health behaviours were a cause or a consequence of depression. Second, factors of health behaviour were self-reported; participants had to respond by relying on their memory, and the responses might not be accurate. Especially, according to previous research, South Korean women tend to hide their real smoking history [44]. This may have affected our results. Third, other health behaviours or environmental factors may also have a hand in the development of depression. However, we analysed the main results including other possible factors as covariates. Fourth, we did not consider the intensity and duration of walking. Lastly, we could not exclude exact patients who had depression, because of the lack of a questionnaire in the CHS. However, we eliminated participants who had a history of expert consultation for sadness or hopelessness that continued more than two weeks in the previous year.

\section{Conclusion}

This study found that influential factors of depression are different for men and women. In addition, participants who did not practise any health behaviours were the most likely to have depressive symptoms. Efforts are underway to manage depression in various ways and according to individual differences. As previously mentioned, depression 


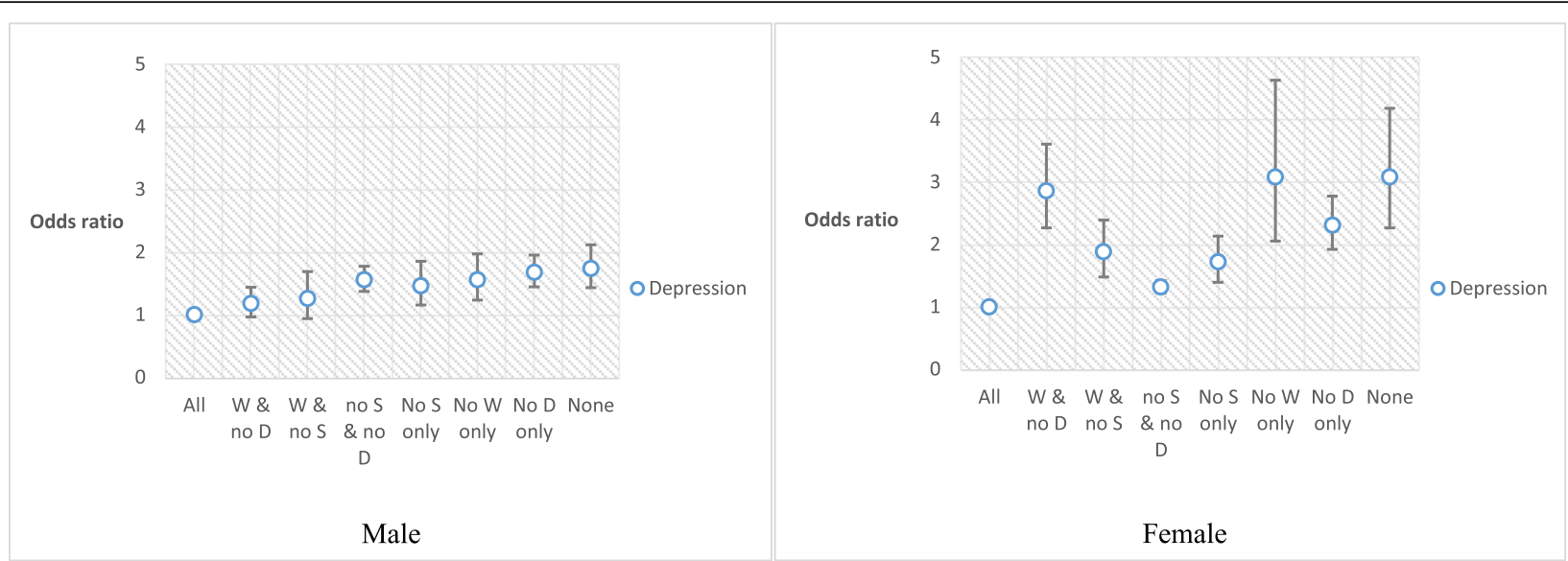

Fig. 2 The results of subgroup analysis stratified by interesting variables

is a significant global health concern and requires social attention and consideration. Therefore, it is necessary to manage depression through interventional methods customised to gender characteristics. Additionally, nationallevel policies are needed to encourage steps to improve personal lifestyles, including practising health behaviours.

\section{Supplementary information}

Supplementary information accompanies this paper at https://doi.org/10. 1186/s12888-020-02628-7.

Additional file 1: Table S1. The results of comparison of model selection statistics among a candidate models. Table S2. The results of subgroup analysis stratified by interesting variables*. Table S3. The results of subgroup analysis stratified by interesting variables.

\section{Abbreviations}

OR: Odds ratio; Cl: Confidence interval; OECD: Organization for Economic Cooperation and Development; PHQ-9: Patient Health Questionnaire-9; CHS: Community Health Survey; VIF: Variance inflation factor

\section{Acknowledgements}

We would like to thank the Korean Centers for Disease Control (KCDC), which conducted and provided data based on nationwide survey. In addition, we would like to thank the colleagues at the Institute of Health Services Research of Yonsei University, who have provided their advice on intellectual content.

\section{Authors' contributions}

BN Jang designed this study, performed statistical analysis, drafted and completed the manuscript. HJ contributed to the concept and design of the study and revised the manuscript. JH provided statistical expertise and interpretation of data. EC Park and SI Jang conceived, designed and directed this study. All authors read and approved the final manuscript.

\section{Funding}

This study was supported by a faculty research grant of Yonsei University College of Medicine (6-2018-0174 and 6-2017-0157).

\section{Availability of data and materials}

The CHS data are openly available at https://chs.cdc.go.kr/chs/index.do by submitting a written statement and data utilization plan.

\section{Ethics approval and consent to participate}

The CHS survey data are openly published, so ethical approval was not applicable for this study. This study did not collect inform consent from the participants, because their information was fully anonymized prior to analysis

\section{Consent for publication}

Not applicable.

\section{Competing interests}

The authors declare that they have no competing interests.

\section{Author details}

'Department of Public Health, Graduate School, Yonsei University, Seoul, Republic of Korea. ${ }^{2}$ Institute of Health Services Research, Yonsei University, Seoul, Republic of Korea. ${ }^{3}$ Department of Preventive Medicine and Institute of Health Services Research, Yonsei University College of Medicine, 50 Yonsei-ro, Seodaemun-gu, Seoul 03722, South Korea.

Received: 20 February 2020 Accepted: 27 April 2020

Published online: 14 May 2020

\section{References}

1. Suicide rates. https://data.oecd.org/healthstat/suicide-rates.htm. Accessed 26 Dec 2019

2. Depression. https://www.who.int/news-room/fact-sheets/detail/depression. Accessed 26 Dec 2019

3. Learn about mental health. https://www.cdc.gov/mentalhealth/learn/index. htm. Accessed 26 Dec 2019.

4. Zhang Y, Chen Y, Ma L. Depression and cardiovascular disease in elderly: current understanding. J Clin Neurosci. 2018:47:1-5.

5. Robinson RG, Jorge RE. Post-stroke depression: a review. Am J Psychiatry. 2016;173(3):221-31.

6. Krebber AM, Buffart LM, Kleijn G, Riepma IC, de Bree R, Leemans CR, Becker A, Brug J, van Straten A, Cuijpers $P$, et al. Prevalence of depression in cancer patients: a meta-analysis of diagnostic interviews and self-report instruments. Psychooncology. 2014:23(2):121-30

7. Sotelo $J$, Musselman D, Nemeroff $C$. The biology of depression in cancer and the relationship between depression and cancer progression. Int Rev Psychiatry. 2014;26(1):16-30.

8. Mitchell AJ, Sheth B, Gill J, Yadegarfar M, Stubbs B, Yadegarfar M, Meader N. Prevalence and predictors of post-stroke mood disorders: a meta-analysis and meta-regression of depression, anxiety and adjustment disorder. Gen Hosp Psychiatry. 2017:47:48-60

9. Kasl SV, Cobb S. Health behavior, illness behavior and sick role behavior: I. health and illness behavior. Arch Environ Health. 1966;12(2):246-66.

10. Barros MBA, Lima MG, Azevedo RCS, Medina LBP, Lopes CS, Menezes PR, Malta DC. Depression and health behaviors in Brazilian adults - PNS 2013. Rev Saude Publica. 2017;51(suppl 1):8s. 
11. Harvey SB, Hotopf M, Overland S, Mykletun A. Physical activity and common mental disorders. Br J Psychiatry. 2010;197(5):357-64.

12. An $R$, Xiang X. Smoking, heavy drinking, and depression among U.S. middleaged and older adults. Prev Med. 2015:81:295-302

13. Cheng HG, Chen S, McBride O, Phillips MR. Prospective relationship of depressive symptoms, drinking, and tobacco smoking among middle-aged and elderly community-dwelling adults: results from the China health and retirement longitudinal study (CHARLS). J Affect Disord. 2016;195:136-43.

14. Davey CG, McGorry PD. Early intervention for depression in young people: a blind spot in mental health care. Lancet Psychiatry. 2019;6(3):267-72

15. OECD. Caring for quality in health. 2017. https://www.oecd.org/els/healthsystems/health-care-quality-reviews.htm. Accessed 26 Dec 2019.

16. Trends in prevalence of depressive disorder among Korean adults aged 19 years and over, 2014 and 2016. https://is.cdc.go.kr/upload_comm/syview/ doc.html?fn=156811337092900.pdf\&rs=/upload_comm/docu/0034/. Accessed 26 Dec 2019

17. Heo YC, Kahng SK, Kim S. Mental health system at the community level in Korea: development, recent reforms and challenges. Int J Ment Health Syst. 2019;13:9.

18. Katon W, Robinson P, Von Korff M, Lin E, Bush T, Ludman E, Simon G, Walker E. A multifaceted intervention to improve treatment of depression in primary care. Arch Gen Psychiatry. 1996:53(10):924-32.

19. Piccinelli M, Wilkinson G. Gender differences in depression: critical review. $\mathrm{Br}$ J Psychiatry. 2000;177(6):486-92.

20. Van de Velde S, Bracke P, Levecque K. Gender differences in depression in 23 European countries. Cross-national variation in the gender gap in depression. Soc Sci Med. 2010;71(2):305-13.

21. Kang YW, Ko YS, Kim YJ, Sung KM, Kim HJ, Choi HY, Sung C, Jeong E. Korea community health survey data profiles. Osong Public Health Res Perspect. 2015;6(3):211-7.

22. Definition of pack year. http://www.cancer.gov/dictionary?CdrID=306510 Accessed 26 Dec 2019

23. Kroenke K, Spitzer RL, Williams JB. The PHQ-9: validity of a brief depression severity measure. J Gen Intern Med. 2001;16(9):606-13.

24. Park S-J, Choi H-R, Choi J-H, Kim K-W, Hong J-P. Reliability and validity of the Korean version of the patient health Questionnaire-9 (PHQ-9). Anxiety Mood. 2010;6(2):119-24.

25. Kario K, Schwartz JE, Davidson KW, Pickering TG. Gender differences in associations of diurnal blood pressure variation, awake physical activity, and sleep quality with negative affect: the work site blood pressure study. Hypertension. 2001;38(5):997-1002.

26. Townsend MH, Bologna NB, Barbee JG. Heart rate and blood pressure in panic disorder, major depression, and comorbid panic disorder with major depression. Psychiatry Res. 1998;79(2):187-90.

27. Veith RC, Lewis N, Linares OA, Barnes RF, Raskind MA, Villacres EC, Murburg MM, Ashleigh EA, Castillo S, Peskind ER. Sympathetic nervous system activity in major depression: basal and desipramine-induced alterations in plasma norepinephrine kinetics. Arch Gen Psychiatry. 1994;51(5):411-22.

28. Amare AT, Schubert KO, Klingler-Hoffmann M, Cohen-Woods S, Baune BT. The genetic overlap between mood disorders and cardiometabolic diseases: a systematic review of genome wide and candidate gene studies. Trans Psychiatry. 2017;7(1):e1007.

29. Badescu SV, Tataru C, Kobylinska L, Georgescu EL, Zahiu DM, Zagrean AM, Zagrean $\mathrm{L}$. The association between diabetes mellitus and depression. J Med Life. 2016;9(2):120-5.

30. Frank RG, Beck NC, Parker JC, Kashani JH, Elliott TR, Haut AE, Smith E, Atwood C, Brownlee-Duffeck M, Kay DR. Depression in rheumatoid arthritis. J Rheumatol. 1988;15(6):920-5.

31. Chien I-C, Lin C-H, Chou Y-J, Chou P. Increased risk of hyperlipidemia in patients with major depressive disorder: a population-based study. J Psychosom Res. 2013;75(3):270-4.

32. Narkiewicz K, van de Borne PJ, Hausberg M, Cooley RL, Winniford MD, Davison DE, Somers VK. Cigarette smoking increases sympathetic outflow in humans. Circulation. 1998;98(6):528-34.

33. Booth FW, Roberts CK, Laye MJ. Lack of exercise is a major cause of chronic diseases. Compr Physiol. 2012;2(2):1143-211.

34. Dickens C, Jackson J, Tomenson B, Creed F. Association of depression and rheumatoid arthritis. Psychosomatics. 2003;44(3):209-15.

35. Lysy Z, Da Costa D, Dasgupta K. The association of physical activity and depression in type 2 diabetes. Diabet Med. 2008;25(10):1133-41.

36. Van Reedt Dortland AK, Vreeburg SA, Giltay EJ, Licht CM, Vogelzangs N, van Veen T, de Geus EJ, Penninx BW, Zitman FG. The impact of stress systems and lifestyle on dyslipidemia and obesity in anxiety and depression Psychoneuroendocrinology. 2013;38(2):209-18.

37. Bonnet F, Irving K, Terra J-L, Nony P, Berthezène F, Moulin P. Depressive symptoms are associated with unhealthy lifestyles in hypertensive patients with the metabolic syndrome. J Hypertens. 2005;23(3):611-7.

38. Gujral S, Aizenstein H, Reynolds CF 3rd, Butters MA, Erickson Kl. Exercise effects on depression: Possible neural mechanisms. Gen Hosp Psychiatry. 2017:49:2-10.

39. Awaworyi Churchill S, Farrell L. Alcohol and depression: evidence from the 2014 health survey for England. Drug Alcohol Depend. 2017;180:86-92.

40. Ströhle A. Physical activity, exercise, depression and anxiety disorders. J Neural Transm. 2009;116(6):777.

41. Robertson $R$, Robertson A, Jepson R, Maxwell M. Walking for depression or depressive symptoms: a systematic review and meta-analysis. Ment Health Phys Act. 2012;5(1):66-75.

42. Sarris J, O'Neil A, Coulson CE, Schweitzer I, Berk M. Lifestyle medicine for depression. BMC Psychiatry. 2014;14(1):107.

43. Arroll B, Goodyear-Smith F, Crengle S, Gunn J, Kerse N, Fishman T, Falloon K Hatcher S. Validation of PHQ-2 and PHQ-9 to screen for major depression in the primary care population. Ann Fam Med. 2010;8(4):348-53.

44. Kang HG, Kwon KH, Lee IW, Jung B, Park EC, Jang SI. Biochemically-verified smoking rate trends and factors associated with inaccurate self-reporting of smoking habits in Korean women. Asian Pac J Cancer Prev. 2013;14(11): 6807-12.

\section{Publisher's Note}

Springer Nature remains neutral with regard to jurisdictional claims in published maps and institutional affiliations.
Ready to submit your research? Choose BMC and benefit from:

- fast, convenient online submission

- thorough peer review by experienced researchers in your field

- rapid publication on acceptance

- support for research data, including large and complex data types

- gold Open Access which fosters wider collaboration and increased citations

- maximum visibility for your research: over $100 \mathrm{M}$ website views per year

At $\mathrm{BMC}$, research is always in progress.

Learn more biomedcentral.com/submissions 